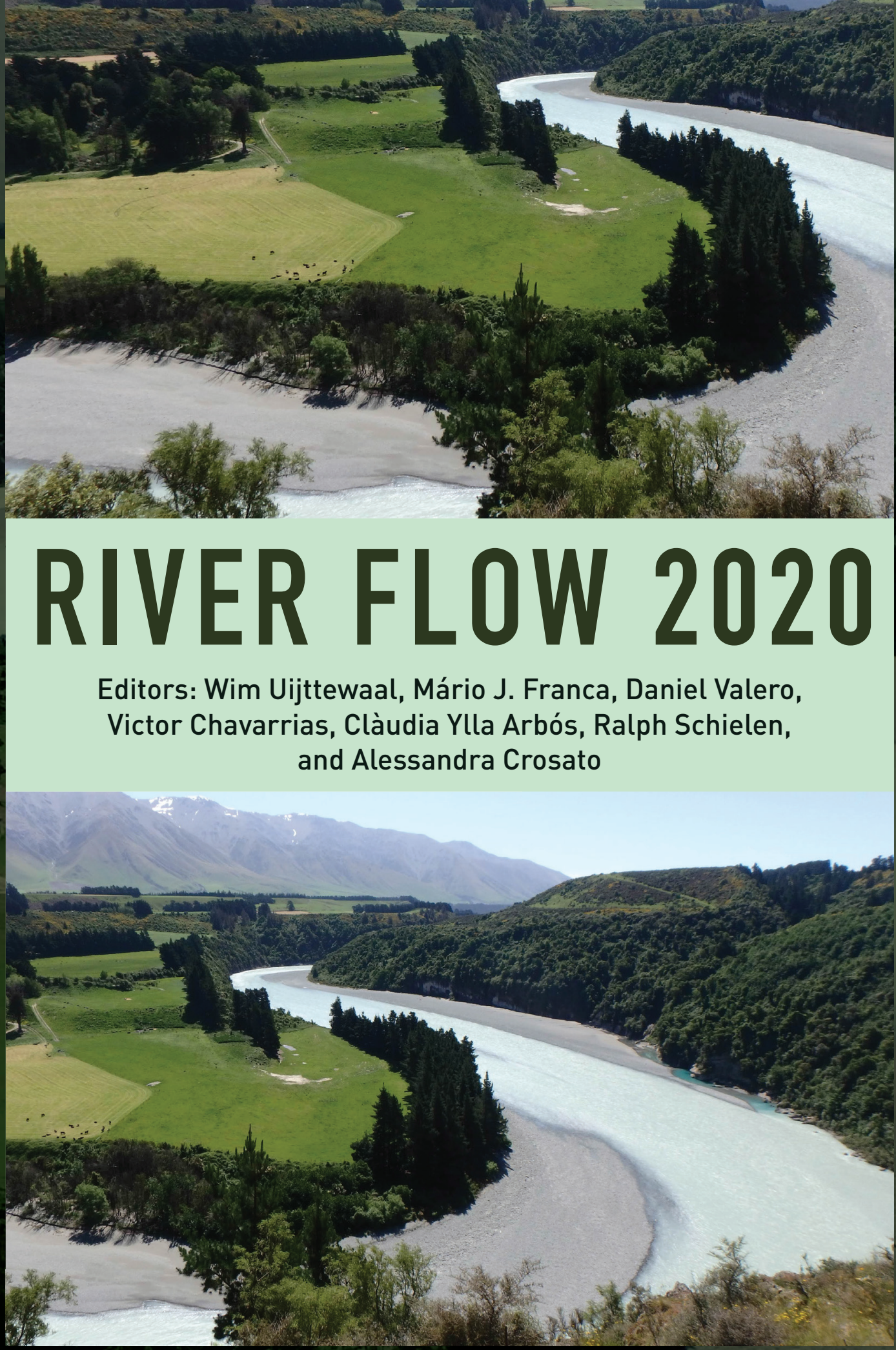


RIVER FLOW 2020 


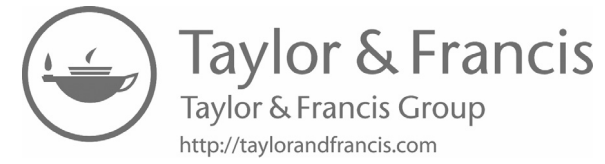




\section{River Flow 2020}

\section{Editors}

\section{Wim Uijttewaal}

Department of Hydraulic Engineering, Faculty of Civil Engineering and Geosciences, Delft University of Technology, Delft, The Netherlands

\section{Mário J. Franca}

IHE Delft Institute for Water Education, Delft The Netherlands

Department of Hydraulic Engineering, Faculty of Civil Engineering and Geosciences, Delft University of Technology, Delft, The Netherlands

\section{Daniel Valero}

IHE Delft Institute for Water Education, Delft, The Netherlands

\section{Victor Chavarrias}

River dynamics and inland water transport, Deltares, Delft, The Netherlands

\section{Clàudia Ylla Arbós}

Department of Hydraulic Engineering, Faculty of Civil Engineering and Geosciences, Delft University of Technology, Delft, The Netherlands

\section{Ralph Schielen}

Ministry of Infrastructure and Water Management-Rijkswaterstaat, Utrecht, The Netherlands Department of Hydraulic Engineering, Faculty of Civil Engineering and Geosciences, Delft University of Technology, Delft, The Netherlands

\section{Alessandra Crosato}

IHE Delft Institute for Water Education, Delft, The Netherlands

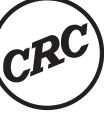


CRC Press/Balkema is an imprint of the Taylor \& Francis Group, an informa business

(C) 2020 Taylor \& Francis Group, London, UK

Typeset by Integra Software Services Pvt. Ltd., Pondicherry, India

All rights reserved. No part of this publication or the information contained herein may be reproduced, stored in a retrieval system, or transmitted in any form or by any means, electronic, mechanical, by photocopying, recording or otherwise, without written prior permission from the publisher.

Although all care is taken to ensure integrity and the quality of this publication and the information herein, no responsibility is assumed by the publishers nor the author for any damage to the property or persons as a result of operation or use of this publication and/or the information contained herein.

\section{Library of Congress Cataloging-in-Publication Data}

Applied for

Published by: CRC Press/Balkema

Schipholweg 107C, 2316XC Leiden, The Netherlands

e-mail: Pub.NL@taylorandfrancis.com

www.crcpress.com - www.taylorandfrancis.com

ISBN: 978-0-367-62773-7 (Hbk)

ISBN: 978-1-003-11095-8 (eBook)

DOI: $10.1201 / \mathrm{b} 22619$

https://doi.org/10.1201/b22619 


\title{
Application of hydroinformatic tools to assess flood flow conditions under a medieval masonry arch bridge
}

\author{
J.L.S. Pinho \& D. Oliveira \\ Department of Civil Engineering, University of Minho, Portugal \\ A.V. Tomé \\ Plengil, Funchal - Madeira, Portugal
}

\begin{abstract}
Medieval arch bridges are important heritage that requires a continuous effort for their preservation. Hydrodynamic actions during flood events have to be properly assessed in order to evaluate their safety status. However, behind the structural aspects, the characterization of their interference in the river flow during extreme events constitutes a challenge task. This paper discusses the hydraulic aspects of a comprehensive study that is being developed to study a medieval masonry arch bridge over Cávado River at the city of Barcelos, Portugal. A set of models were implemented involving different spatial scales in order to characterize different river hydrodynamic scenarios including floods and normal regimes to be considered during the planned restoration work. A river basin model was implemented in Sobek software to propagate flood hydrographs from the upstream reservoir until the bridge river section. A two-dimensional hydrodynamic model was implemented to simulate the bridge river area using Delft3dFM software. Finally, a 3D model was set-up in FLOW-3D software to analyze the loads of the river flow over the masonry bridge. Details of the methodology used in the modelling approaches are presented together with simulated results. These results will be analyzed together with the observed consequences for the bridge structure damages that are precious testimonials of the intensity associated with historical flood events.
\end{abstract}

\section{INTRODUCTION}

Medieval masonry arch bridges constitute important heritage testimonials either in terms of its inherent architectonic and historical value or as river engineering technical resilient solutions. Their long life implies that they were subject to a wide range of loads and environmental situations, including extreme events like floods. These events can be responsible for a considerable number of damages including their collapse, usually associated with local foundations scour or even due to arch failure (Lourenço and Oliveira, 2006). Masonry arch bridges are still frequent and they require proper monitoring and conservation programs in order to continuously assess their stability and anticipate possible structural problems. These programs are normally completed with advanced geometry and materials characterization (Barazzeti et al., 2016b; Solla et al., 2010; Lubowiecka et al., 2009) and detailed structural analysis based on numerical models (Conde et al. 2017; Barazzetti et al., 2016a; Riveiro et al., 2011).

Structural analysis usually considers different load conditions. Self-weight of the materials (masonry and fill), moving loads composed by a set of moving static loads associated with a design vehicle and even horizontal loads resulting from earthquakes (Bertolesi et al., 2017; Beconcini et al., 2016). Although hydrodynamic forces during flood events can result in severe bridge damage beyond foundations scour, its consideration in the structural analysis is rare. This is due to two main different reasons: (i) difficulty to predict flood flow characteristics at the river bridge location; (ii) when it can be predicted, additional difficulties arise from the limited capacity to analyze hydrodynamic pressures and stresses around the bridge structure. In the near future, 
these dynamic loads can be aggravated since extreme events associated with climate change are expected to increase peak flood discharges in some basins, which requires a sound hydrologic and hydrodynamic analysis (Hettiarachchi et al., 2018). These analyses can be achieved using proper hydroinformatic tools (eg. Chang et al., 2019; Pinho et al., 2019; Pinho et al., 2014).

River basin hydrological processes can be approached by simplified physical formulations that can be solved by numerical methods. A similar approach can be followed to propagate hydrographs along the river network to bridge locations. Water levels, hydrodynamic pressures and flow velocities can be further detailed using three-dimensional hydrodynamic models of the river section at the bridge location. However, available software solutions do not allow to implement such a complete and detailed analysis of all the hydrological processes and spatial scales associated with the characterization of hydrodynamic loading on masonry medieval bridges. Only a hydroinformatic environment that comprises specific sets of software packages adequate for each one of the involved hydrologic processes and spatial scales could be used to simulate such loads.

This paper presents a proposal of a hydraulic modelling approach involving three software packages that can be used to study and characterize the river flow regimes and local hydrodynamics features resulting from fluid-bridge interaction. The hydroinformatic environment capabilities are illustrated with its application to the hydrodynamic analysis of the Barcelos medieval bridge.

\section{METHODS}

\subsection{Barcelos medieval arch bridge}

The medieval masonry arch bridge of Barcelos crosses the river Cávado and links Barcelos to Barcelinhos (Figure 1). This bridge was built between 1325 and 1328. The crossing point of the river Cávado was strategically chosen over a granite rocky outcrop. Immediately downstream of the bridge there is an old granite masonry weir that influences the river water levels at the bridge location, but it is currently partially destroyed.

The bridge is made up of five arches and four piers, reinforced with triangular upstream cutwaters and rectangular downstream cutwaters. The bridge has a flat deck with a total length of $94 \mathrm{~m}$ and a width of $6 \mathrm{~m}$. It has been classified as a national monument since 1910 , because of its historical and monumental values.

Throughout its history, the bridge has been subject to successive modifications, referring below some of the most relevant interventions:

- 1630: works for widening and flattening the deck and placing a masonry parapet;

- 1800: collapse of the tower of the bridge and part of the palace of the Counts of Barcelos that was linked to it, seriously affecting the structure of the bridge, on its north side, having been undertaken works of recovery of the bridge;

- 1881: widening of the deck and replacement of the masonry parapet with the current iron guards, and new pavement;

- 1960: occurrence of floods, with the water level practically reaching the crown of the highest arches. This event was the basis of the intervention carried out in 1961, which consisted essentially of structural reinforcement of two arches and a spandrel wall with metallic elements, on the upstream and downstream sides of them, and repointing of cracks in the arches with cementitious mortars;

- 1980s: Heavy traffic on the bridge became conditioned.

A recent inspection detected some damage of foundations masonry joints that motivated a comprehensive characterization and diagnostic of the structural performance of the bridge, including the assessment of the flow interaction with the structure.

\subsection{Hydroinformatic tools}

The flow characteristics at a specific river location can be obtained by measurements, but they must be long enough to include extreme events. Alternatively, a set of hydrological and 

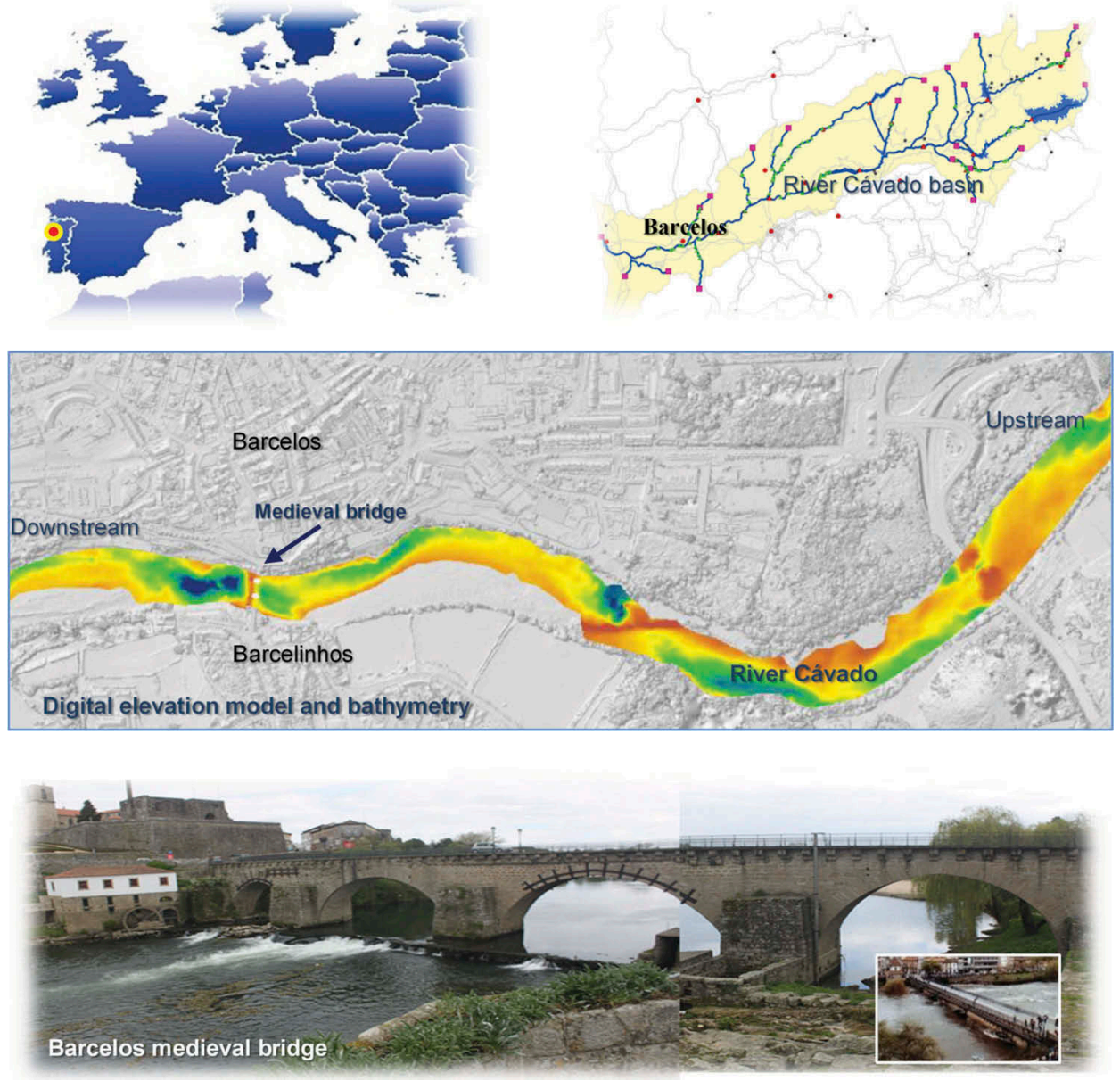

Figure 1. Study site location, topographic/bathymetric data and Barcelos medieval bridge photo.

hydrodynamic models could be used to simulate the river flow details at that location. In general, a river hydrodynamic model is required to propagate river hydrographs from an upstream river gauge station till the bridge section. In this work the Sobek software (Deltares, 2011) was applied to implement a one-dimensional (1DH) river hydrodynamic model. This software solves the one-dimensional formulations of free surface flows based on the continuity and conservation of momentum equations. In addition to these equations the flow discharges at hydraulic structures included in the model segmentation are computed using specific expressions for each type of structure: bridges, culverts, siphons, orifices, pumps, and weirs. In these structures the flow depends on the upstream and downstream levels, on its dimensions and on a set of specific parameters. This approach is not sufficient if lateral constrictions due to the bridge piers and abutments are conditioning the flow characteristics (water levels and flow velocities) as is the case of the medieval bridge under study.

More detailed and realistic flow characteristics can be obtained if a two-dimensional hydrodynamic model is applied. This approach requires continuous topographic and bathymetric data for the riverbed and banks instead of discrete cross-section elevation data which is the case for a one-dimensional river model. Delft3DFM (Deltares, 2018) was used for implementation of a two-dimensional (2DH) model of the river stretch around the medieval bridge. It is a hydrodynamic simulation program suite for a multi-disciplinary approach for coastal, river and estuarine areas. It can carry out simulations of flows, waves, water quality and ecology. The $2 \mathrm{DH}$ model is appropriate for a detailed flow characterization if the geometric 
constrictions introduced by the bridge are constant when the water level rises. This is not the case of the studied bridge. This way an additional 3D hydrodynamic model was implemented to characterize the flow around the bridge.

This model was implemented with FLOW-3D software (Hirt and Nichols, 1981). This is a general-purpose computational fluid dynamics (CFD) software based on the finite volume method that derives directly from the integral form of the conservation laws for fluid motion. It uses the Volume of Fluid (VOF) numerical method, consisting of three main components: the definition of the volume of fluid function, a method to solve the VOF transport equation and setting the boundary conditions at the free surface.

\subsection{Cascade of implemented models}

The set of models were implemented in a sequential way starting with the 1DH model (see also Figure 2). It comprises 1722 computational nodes, 22 open boundaries, 51 controlled discharges at hydraulic structures and 105 non controlled hydraulic structures. The river channels geometry was introduced by considering 1854 cross sections. All hydraulic structures with a significant influence in the river flows regime were considered with emphasis for dams and hydropower generation plants. The segmentation of the model was defined considering the important influence of the upstream reservoirs in the river flows and the intense occupation of the basin in the downstream areas. Results of the $1 \mathrm{DH}$ model were used to define conditions at the open boundaries of the $2 \mathrm{DH}$ model.
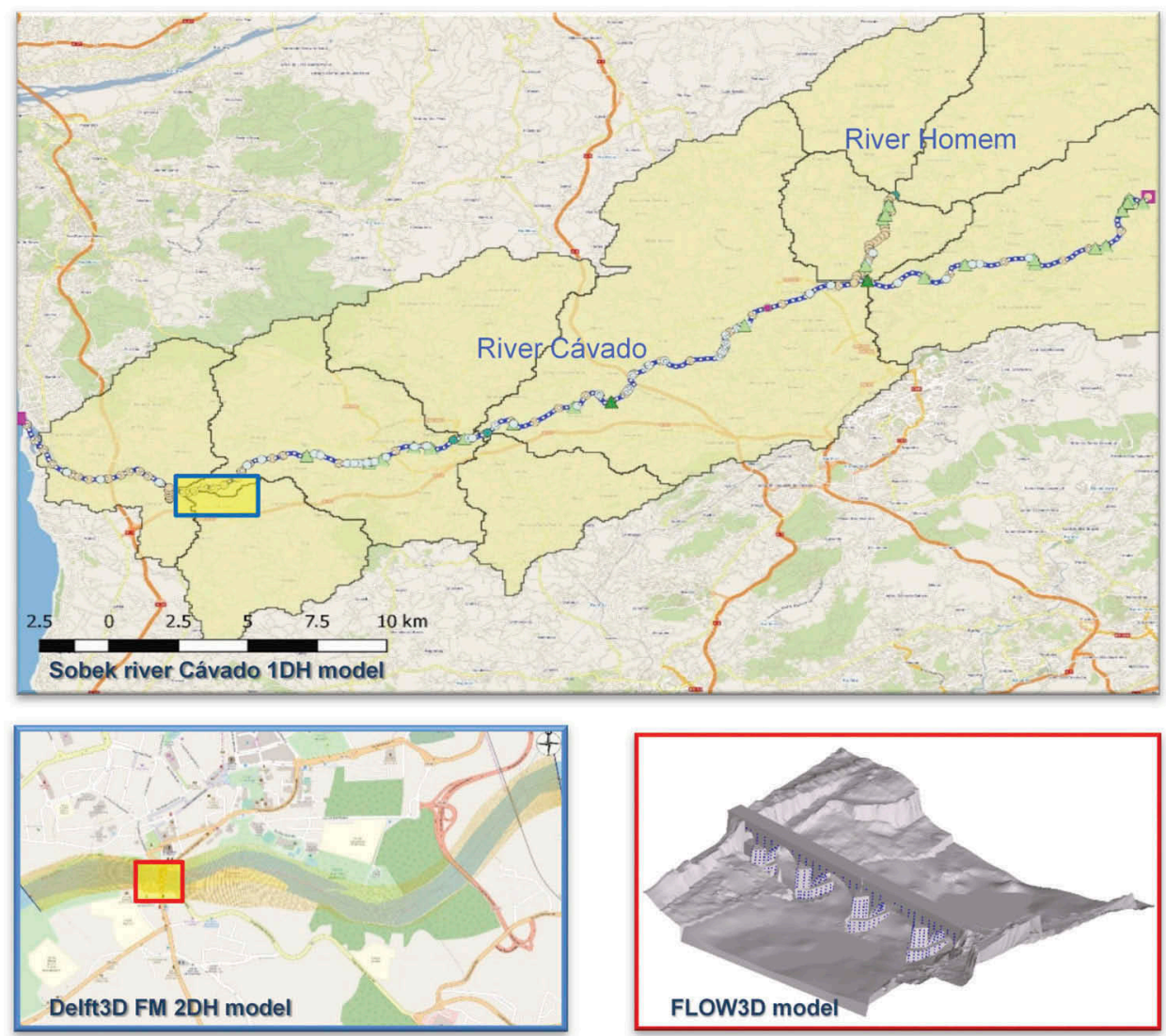

Figure 2. Cascade of implemented models: Sobek 1DH river model, Delft3D FM local 2DH model (blue rectangles) and FLOW-3D river and medieval bridge model (red rectangles). 
2DH model covers a domain that includes the area of the bridge extending upstream and downstream to locations far enough from the bridge in order to avoid the influence of the simplified assumed conditions at the open boundaries: discharge at upstream and water level at the downstream boundary. The model was discretized with an unstructured grid composed of quads and triangles.

The three-dimensional model was implemented to assess the three-dimensional features of the river flow under the bridge and its interactions with the bridge structure. The bridge geometry was defined using data derived from a laser camera survey and bathymetric data. Model domain was discretized with a unique block of 13204512 cubic cells of $0.25 \mathrm{~m}$ side. Turbulence was modelled using a two transport equations for the model turbulent kinetic energy ( $k-\varepsilon$ model). This model has been shown to provide reasonable approximations to many types of flows (Isfahani and Brethour, 2009). A non-slip or partial slip condition was adopted for wall boundary conditions.

Boundary conditions were imposed at the upstream and downstream block faces. The values at the boundaries were estimated based on equivalent simulations performed with 1DH and $2 \mathrm{DH}$ models.

\section{RESULTS}

\section{1 $1 \mathrm{DH}$ and $2 \mathrm{DH}$ models}

Water levels associated with flood events simulated by the two models (1DH and 2DH) are relatively close (Table 1). The highest values obtained with the $2 \mathrm{DH}$ model result from the contraction to the flow caused by the insertion of the bridge piers. This effect was not considered in the implementation of the $1 \mathrm{DH}$ model. The piers have a significant impact in the flow since they occupy a relevant area of the river cross section. It is very difficult to tune a 1DH model to properly simulate the flow under the parallel bridge arches, unless we have floods measured data to calibrate the necessary parameters of the hydraulic structures used to discretize those arches. This way, this two models (1DH and 2DH) approach allow to better assess the influence of the piers, requiring, however, an additional modeling effort.

Both $1 \mathrm{DH}$ and 2DH models were applied to simulate frequent river flow conditions. In the first case, a weir discharge law was defined and the effect of the bridge pillars was neglected. In the case of the $2 \mathrm{DH}$ model the levels are simulated considering the effect of the piers on the flow.

Based on the hourly time series of the discharged flows at the upstream dam for the period between January 1997 to January 2019, the characteristic rivers flow discharges values associated with different duration curve percentages were computed. These flow discharges served as a reference to simulate the frequent levels downstream and upstream of the medieval bridge. Table 2 presents the obtained results.

It is noted that, for the analyzed frequent flow range, the flow conditions are determined by the weir, and the influence of the piers is not significant in terms of the upstream water surface elevation. It should also be noted that, since the river flow regime at this stretch of the river

Table 1. $1 \mathrm{DH}$ and 2DH models simulated water levels (WL) for peak flood river discharges.

\begin{tabular}{rccc}
\hline Return Period (years) & Discharge $\left(\mathrm{m}^{3} / \mathrm{s}\right)$ & Upstream WL 1DH $(\mathrm{m})$ & Upstream WL 2DH $(\mathrm{m})$ \\
\hline 2 & 505 & 8.08 & 8.32 \\
5 & 764 & 9.02 & 9.30 \\
10 & 934 & 9.58 & 9.86 \\
20 & 1096 & 10.07 & 10.35 \\
50 & 1306 & 10.69 & 10.95 \\
100 & 1464 & 11.13 & 11.38 \\
\hline
\end{tabular}


Table 2. 1DH and 2DH simulated water levels (WL) for frequent discharges.

\begin{tabular}{lllll}
\hline $\begin{array}{l}\text { Duration-curve } \\
(\%)\end{array}$ & $\begin{array}{l}\text { Discharge } \\
\left(\mathrm{m}^{3} / \mathrm{s}\right)\end{array}$ & $\begin{array}{l}\text { Downstream WL } \\
(\mathrm{m})\end{array}$ & $\begin{array}{l}\text { Upstream WL } \\
1 \mathrm{DH}(\mathrm{m})\end{array}$ & $\begin{array}{l}\text { Upstream WL } \\
2 \mathrm{DH}(\mathrm{m})\end{array}$ \\
\hline 5 & 84 & 3.31 & 5.93 & 6.01 \\
40 & 45 & 2.62 & 5.72 & 5.65 \\
50 & 32 & 2.15 & 5.57 & 5.51 \\
65 & 1 & 1.57 & 5.15 & 5.02 \\
\hline
\end{tabular}

Cávado is determined by the operation of an upstream dam (with turbines capacity of approximately $2 \times 30 \mathrm{~m}^{3} / \mathrm{s}$ ), the water level at the medieval bridge will vary between $5.15 \mathrm{~m}$ and $6.00 \mathrm{~m}$, when the tributary river flows, between the upstream dam and the bridge river section, are negligible.

The flow velocities were simulated for different river flow discharges. Values corresponding to estimated peak flood flows (Q) at the medieval bridge section were selected (Table 1). Maximum values occur over the weir crest, as would be expected, reaching maximum values of vertical averaged velocities modules $(U)$ of the order of $8 \mathrm{~m} / \mathrm{s}$ for the highest peak flows (Figure 3).

\subsection{3 model}

River flow and structure interactions results, simulated with the 3D local model, allows to obtain a detailed characterization of the three-dimensional features of the flow under the medieval bridge (Figure 4). It can be noted the flow accelerate under the bridge arches which leads to intense velocities around the foundations and piers. Hydrodynamic pressures were obtained for a set of probe points defined around the bridge. This way simulated pressures are used in the structural analysis based on a finite element model of the bridge. An example of the obtained pressures is presented in Figure 5, at five points at the different faces of pier 2.
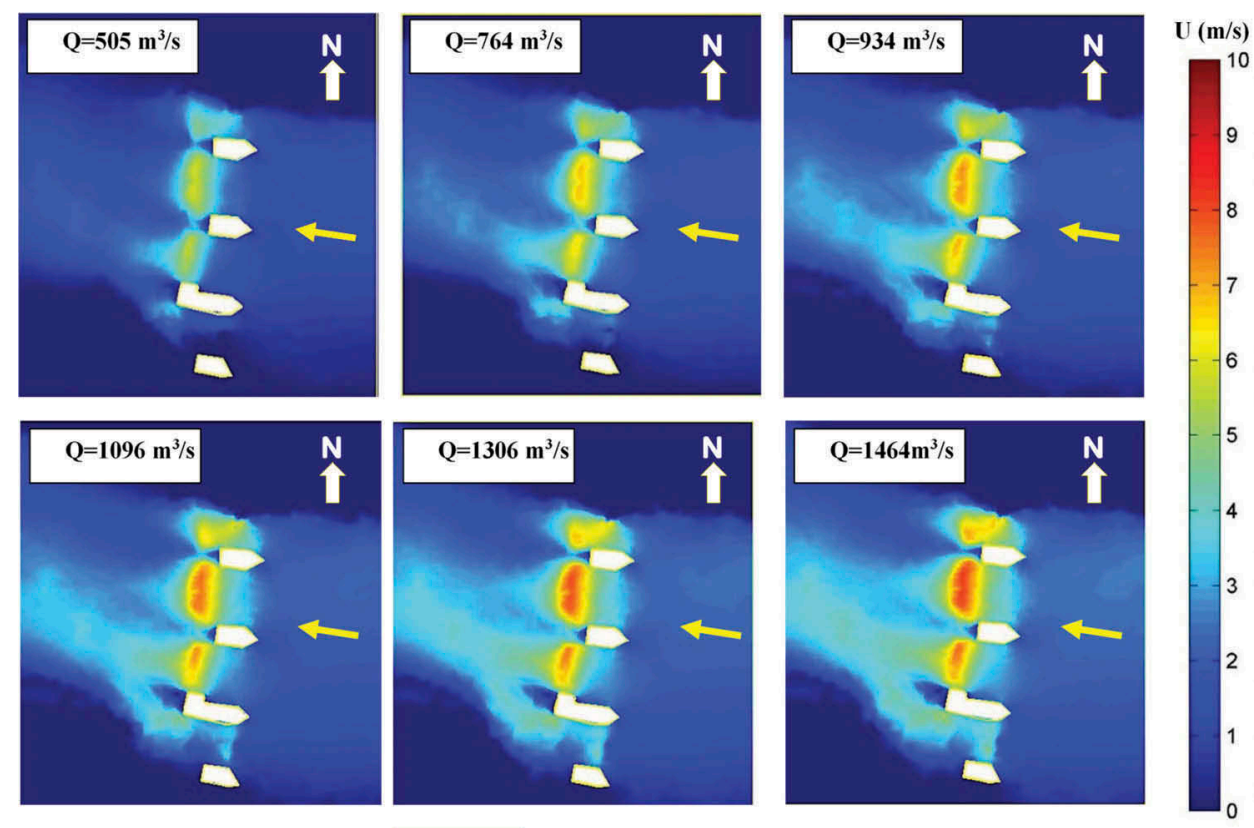

$\leftarrow$ - River flow direction

Figure 3. 2DH model depth averaged velocities module (U) results for flood peak discharges (Q). 

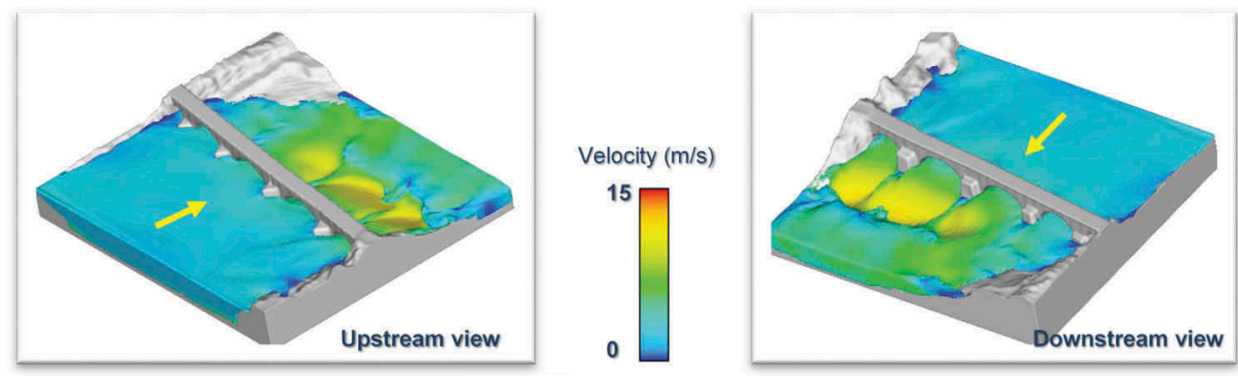

- River flow direction
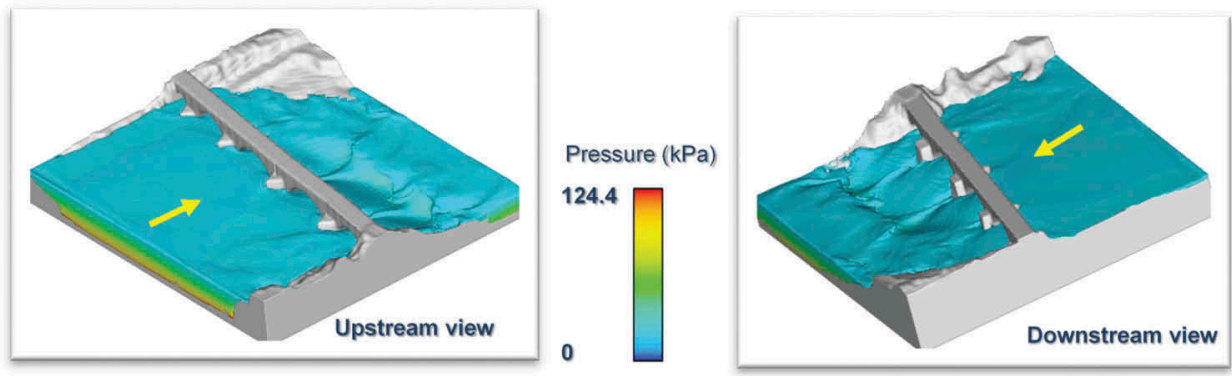

Figure 4. 3D model results: velocities (upper panels) and pressures (lower panels).

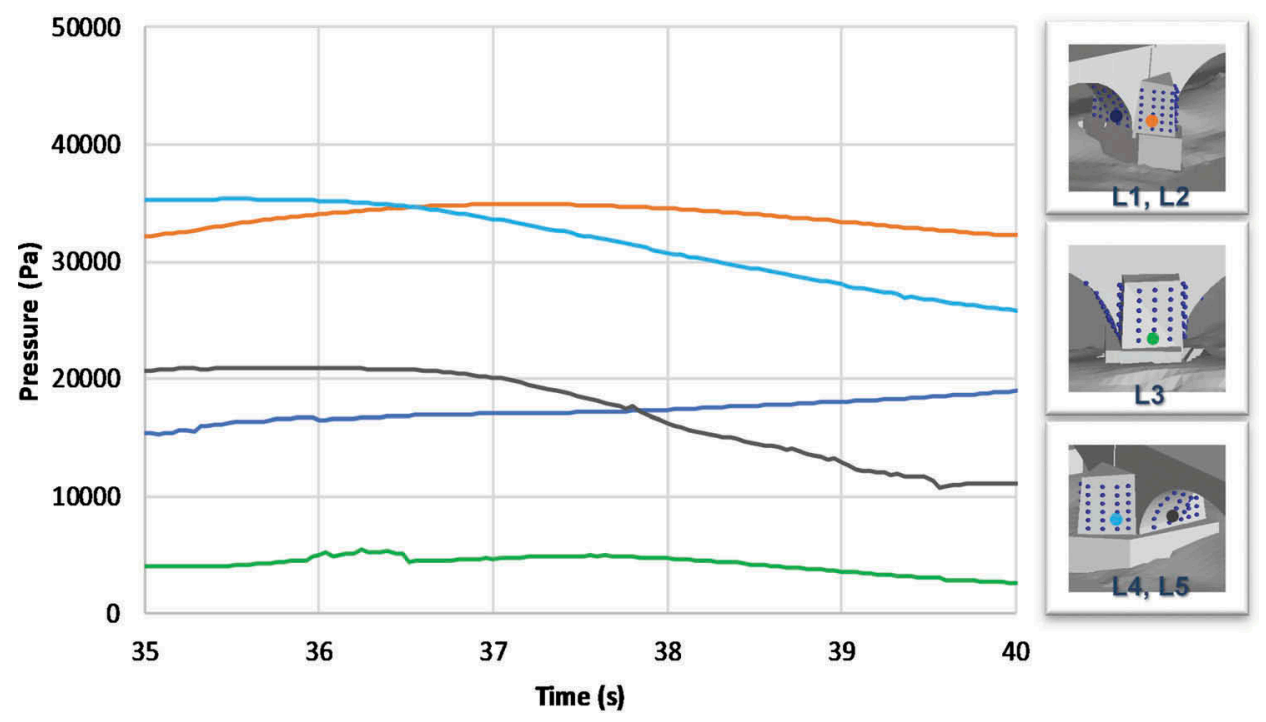

$-\mathrm{L} 1-\mathrm{L} 2-\mathrm{L} 3-\mathrm{L} 4-\mathrm{L} 5$

Figure 5. Illustrative pressures results to be used in the structural analysis. The graph presents the last $5 \mathrm{~s}$ of a $40 \mathrm{~s}$ simulation that starts from an empty river channel as initial condition and allows to achieve a quasi-steady regime. 


\section{CONCLUSION}

A comprehensive methodological approach based on the integration of different hydroinformatic tools was designed and successfully applied to analyze the flow characteristics under a medieval masonry arch bridge. The river flow characteristics in terms of surface water elevations, velocities and dynamic pressures and tangential stresses were simulated for a particular river section that is dependent on the structure interference. This approach, or a similar one, can be followed in order to assess the consequences of extreme flood events associated with climate change scenarios.

Presented work demonstrate that it is possible to simulate detailed hydrodynamic loads in a problem involving fluid-structures interaction with a relatively reasonable computational effort. Those loads are usually roughly estimated or neglected in the presence of other horizontal loads (eg., seismic loads). This detailed analysis is justified when the structure has an interest behind its functionality like historical and architectonic values and must be preserved using non-intrusive rehabilitation techniques. The work will proceed with the analysis of the fluid-structure interaction, based on the structural finite element model of the masonry arch bridge and using the pressures and tangential stresses simulated with the 3D hydraulic model. Moreover, tangential flow stresses simulated with the 3D flow model will be used to design the piers foundation protection.

However, the cascade of models still present several sources of uncertainty related with the adopted simplifications in the hydraulic processes and gaps in required data for proper calibration of the models parameters. Therefore, it is advised to install adequate sensors that can be used to continuously monitor either the bridge response and also the river flow loads, taking advantage of the actual IoT knowledge and solutions and moving forward the hydraulic and structural domains to the digital era.

\section{REFERENCES}

Barazzetti, L., Banfi, F., Brumana, R., Previtali, M., \& Roncoroni, F. (2016a). Integrated Modeling and Monitoring of the Medieval Bridge Azzone Visconti. In Proceedings of the 8th European Workshop on Structural Health Monitoring (EWSHM 2016), Bilbao, Spain (pp. 5-8).

Barazzetti, L., Banfi, F., Brumana, R., Roncoroni, F., \& Previtali, M. (2016b). BIM from laser scans... not just for buildings: NURBS-based parametric modeling of a medieval bridge. In XXIII ISPRS Congress, Commission V (pp. 51-56).

Beconcini, M. L., Croce, P., Marsili, F., Muzzi, M., \& Rosso, E. (2016). Probabilistic reliability assessment of a heritage structure under horizontal loads. Probabilistic engineering mechanics, 45, 198-211.

Bertolesi, E., Milani, G., Lopane, F. D., \& Acito, M. (2017). Augustus Bridge in Narni (Italy): seismic vulnerability assessment of the still standing part, possible causes of collapse, and importance of the Roman concrete infill in the seismic-resistant behavior. International Journal of Architectural Heritage, 11(5), 717-746.

Chang L-C, Chang F-J, Yang S-N, Kao I-F, Ku Y-Y, Kuo C-L, Amin IMZM (2019) Building an Intelligent Hydroinformatics Integration Platform for Regional Flood Inundation Warning Systems. Water. MDPI. 11(1):9.

Conde, B., Ramos, L. F., Oliveira, D. V., Riveiro, B., \& Solla, M. (2017). Structural assessment of masonry arch bridges by combination of non-destructive testing techniques and three-dimensional numerical modelling: Application to Vilanova bridge. Engineering Structures, 148, 621-638.

Deltares. (2011). SOBEK - Reference Manual. Delft Hydraulics, Netherlands. Deltares.

Deltares. (2018). Delft3D FM Suite 2018- User Manual. Deltares, Netherlands.

Hettiarachchi, S., Wasko, C., \& Sharma, A. (2018). Increase in flood risk resulting from climate change in a developed urban watershed-the role of storm temporal patterns. Hydrol. Earth Syst. Sci., 22, 2041-2056.

Hirt, C. W., \& Nichols, B. D. (1981). Volume of fluid (VOF) method for the dynamics of free boundaries. Journal of computational physics, 39(1), 201-225.

Isfahani, A. H. G., \& Brethour, J. M. (2009). On the implementation of two-equation turbulence models in FLOW-3D. Flow Science. FSI-09-TN86. 
Lourenço, P. B., \& Oliveira, D. V. (2006). Strengthening of masonry arch bridges: research and applications. Proceedings of the First International Conference on Advances in Bridge Engineering. Editors A. Kumar, C. J. Brown, L. C. Wrobel. Brunel University. ISBN:1902316495.

Lubowiecka, I., Armesto, J., Arias, P., \& Lorenzo, H. (2009). Historic bridge modelling using laser scanning, ground penetrating radar and finite element methods in the context of structural dynamics. Engineering Structures, 31(11), 2667-2676.

Pinho, J.L.S., Vieira, L., Vieira, J. M. P., Venâncio, S., Simões, N. E., Sá Marques, J. A., \& Santos, F. S. (2019). Assessing causes and associated water levels for an urban flood using hydroinformatic tools. Journal of Hydroinformatics. IWA Publishing.

Pinho, J.L.S.; Ferreira, R.; Vieira, L.; Schwanenberg, D., (2014) Comparison Between Two Hydrodynamic Models for Flooding Simulations at River Lima Basin, Water Resources Man-agement, doi:10.1007/s11269-014-0878-6.

Riveiro, B., Caamaño, J. C., Arias, P., \& Sanz, E. (2011). Photogrammetric 3D modelling and mechanical analysis of masonry arches: An approach based on a discontinuous model of voussoirs. Automation in Construction, 20(4), 380-388.

Solla, M., Lorenzo, H., Novo, A., \& Rial, F. I. (2010). Ground-penetrating radar assessment of the medieval arch bridge of San Antón, Galicia, Spain. Archaeological prospection, 17(4), 223-232. 